\title{
Corporate Social Responsibility and Global Brands Commitment
}

\author{
Maria Skivko $^{1, *}$, Elena Korneeva ${ }^{2,3}$, Kirill Gerasimov ${ }^{1}$ \\ ${ }^{1}$ Samara National Research University, Samara, Russia \\ ${ }^{2}$ Financial University under the Government of the Russian Federation, Moscow, Russia \\ ${ }^{3}$ Togliatti State University, Togliatti, Russia \\ *Corresponding author. Email: maria.skivko@gmail.com
}

\begin{abstract}
This paper focuses on the notion of corporate social responsibility and investigates the interconnection between the negative environmental impact and business activities of global corporations. In particular, the paper analyzes the engagement of some global brands in the sustainable development discussion. In the cases of annual environmental reports, this paper explores the brands' commitment to the reducing the ecological footprint, applying energy efficiency principles and using renewable energy.
\end{abstract}

Keywords: corporate social responsibility, sustainable development, sustainability report, global corporations, ecological footprint, energy efficiency, renewable energy.

\section{INTRODUCTION: ENVIRONMENTAL PROBLEMS AND GLOBAL BRANDS IMPACT}

The discussion on environmental problems and sustainable development nowadays embrace all the spheres of human life, from private households influence to the global corporations' performance. Pollution, waste disposal, climate change, water contamination, loss of biodiversity and other environmental problems are deeply interconnected with human's activities. For example, some of the largest global fossil fuel corporations contribute to $35 \%$ of all energy-related carbon dioxide and methane worldwide [1]. Plastics packaging for many different products is one of the biggest global environmental problems cause only $14 \%$ of it is currently recycled - the rest stays at the landfills and increases water and soil pollution. Various global companies' pollution ratings can significantly change the brand image and reputation [2]. Consumers also pay more and more attention to the brands' involvement in the sustainable actions and require more sustainable products and services.

The importance of changes, a more conscious approach to consumption and business and the need for concrete sustainable actions are evident for everyone. If individuals contribute by various sustainable practices and actions at the level of private households, small and large companies have to perform their sustainable attitudes more publicly and transparently. In particular, business leaders create, evaluate and implement different strategies and ideas to contribute to the discussion of sustainable development [3]. Moreover, providing positive changes on key environmental problems is suitable for companies and consumers; it improves the company's reputation and opens certain opportunities for further development [4]. So, different changes concerning raw materials extraction, manufacturing, packaging, transportation or efficient resource use for lowering negative environmental impact slowly become habitual in small, medium and large companies worldwide.

Several initiatives and documents (e.g., The Global Reporting Initiative, The United Nations Global Compact, The Leadership in Energy and Environmental Design) have been launched to consider environmental challenges, promote more sustainable technologies and solutions and encourage large and small companies to join and contribute. Those transformations at the global market signify the switch from a linear economy to a circular economy by better using the resources and minimizing waste production, by maximizing the product value and allowing its reuse or recycling. Moreover, those changes concern manufacturing, product lines, customer offers, customer relations, packaging, and supply chain.

One of the ways to represent all those sustainable contributions and reflect the transformation at all levels of the production process is to implement the term corporate social responsibility in the daily business routine. 
This article focuses on the analysis of three indicators, ecological footprint, energy efficiency and renewable energy, performed in the environmental reports for 2020 of such global corporations as H\&M (fashion), Siemens (technologies) and Apple (mobile devices).

\section{CORPORATE SOCIAL RESPONSIBILITY}

Among the variety of definitions of corporate social responsibility, it is essential to focus on the company's social engagement to compensate for the negative environmental impact. As an essential aspect of social and environmental accountability, corporate social responsibility (CSR) is a business model that includes various social, economic and environmental practices and policies that help a company be socially accountable. Additionally, CSR is explained through the switch from pure profits to certain social interests. It can be beneficial to the company itself as well as to stakeholders, investors and citizens concerning socially responsible investment, the fair-trade movement, or the intention to be employed by a socially responsible institution. Corporate social responsibility is important to both consumers and companies. At the level of large corporations, it is crucial to elaborate business standards and regulations to fulfil the demands of stakeholders and increase involvement in global environmental discussion [5].

It is always a question for scientific discussion to define the scope to which corporate social responsibility can be applied emphasising the difference between socially responsible and corporate image management [6]. Business communities always concern about their reputation, public image, and the possibilities for its improvements cause it relates the long-term story with profits. CSR expresses the company's visibility, transparency and responsibility. Murphy classifies the relation to CSR practices and defines the era of charity, awareness, issue and responsiveness [7]; each era symbolises the changes in companies concerning the socially responsible business ideas. Caroll declares that since 2000 s, the idea of corporate social responsibility became a global phenomenon that involves different ideas from stakeholder theory, business ethics, sustainability, and corporate citizenship [8].

Corporate social responsibility can include strategies and practices that improve and balance the relations between human beings and the environment, that improve economic benefits without harming natural resources. Main CSR activities include incorporating environmental management in the manufacturing processes, improving the efficient use of resources, and reducing waste production and carbon emissions. Moreover, it embraces the initiatives for employee empowerment by improving labour standards and working conditions, creating community relations, and incorporating the principles of social equity, gender balance and protect- ing human rights. Furthermore, brands' social performance includes the stakeholders' demand for corporate social responsibility and their active participation in those practices, as well as sharing a common understanding of corporate activities and value system $[9,10]$.

For instance, Benabou and Tirole [11] offer three dimensions in which CSR can be applied. Firstly, the "win-win" situation relates changes in the management system by settling down the long-term perspective in the use of resources, the investments, the position at the market. Secondly, the stakeholders demand engaging in philanthropy that can be delegated through the company's performance. Here the CSR practices can be used as direct support, social or financial help, or compensation from the own negative environmental impact. On the one hand, it can improve the corporate social image; on the other hand, there is a lot of space for greenwashing. Finally, insider-initiated CSR can be understood as demanded from the management or board member team.

Generally, CSR aims to represent three ideas. Firstly, the focus on philanthropy; a company concentrates not on profits or production improvements but donations of money or equipment to civic organisations, engagement with community initiatives, and support for employee volunteering. Secondly, focus on improving operational effectiveness; a company aims to deliver social or environmental benefits that support a company's operations across the value chain, improving efficiency and effectiveness (initiatives that reduce resource use, waste, or emissions, costs; investments in employee working conditions, health care, or education, which may enhance productivity, retention, and company reputation). Thirdly, focus on transforming business model; a company is created under new business forms (e.g., social entrepreneurship).

Typical reporting consists of three main scopes: vision and goals, management approach, and performance indicators [12]. In different cases, it is possible to recognise whether the CSR reporting was enough transparent and substantive to represent environmental and social contribution. Among the different benefits of working on a corporate social responsibility report, it is possible to emphasise the positive influence on the company's reputation (by restoring profitability) and improve customer relations (by increasing customer loyalty). Hence, it also includes additional costs (expenses by changes in equipment, technologies, supply chain) that not every stakeholder wish to accept.

However, as far as the company's values are often measured through the presented data transparency, even the leaders of CSR performance can fail in this task [13]. Many examples, especially global corporations, demonstrate that some companies focus more on the performance and public image and less on the real actions and changes. So, corporate social responsibility lay 
under consideration and approval. Among certain practices of CSR performance, it is possible to define some steps for institutionalisation as, for instance, compelled performance by social pressure, reporting as a social and business norm and benefited reporting [14]. Nevertheless, it is still not enough to provide a clear perspective and transparency in these questions. In other words, there is a strong need for CSR institutionalisation at the global level and in the international context.

\section{ANALYSIS OF CASES: CSR REPORTS AND GLOBAL CORPORATIONS}

This paper explores companies' sustainability reports for the year 2020, focusing on the ecological footprint, energy efficiency, and the use of renewable energy. The reports usually represent the companies contribution against climate change, global warming and resource depletion; it is expected to discover there the information about implemented new technologies, lowcarbon design, investment in sustainable solutions.

There are three global companies under investigation in this paper. Firstly, H\&M Group (Sweden) consists of such fashion brands as H\&M, COS, Weekday, Monki, H\&M HOME, \& Other Stories, ARKET and Afound. The fashion industry, for instance, occupies second place in the global range of world pollution at each stage of the garment lifecycle (from preparing the raw materials to the transportation and after-use). This company has received much critics from the consumers, stakeholders and ecoactivists regarding their performance in the sustainable discussion $[15,16]$. So, the fashion brand aims to implement the changes in the whole production process and provide public information of those transformations. The "Sustainability Performance Report 2020" [17] provides brands's goals and performance in 2020. The data in this document is confirmed by the auditors' report made by authorised public accountants. It is declared in the report that the company, with its 8 fashion brands and several business initiatives, offer possibilities of implementation of sustainable habits and lifestyle. Moreover, this report for the year 2018 was named the first runner up for the Best Report award in the Creativity in Communications and Relevance \& Materiality categories. H\&M Group proposes a sustainable strategy that includes promoting social innovation and increasing transparency, developing the principles of circular economy and contributing the climate change, promoting fair working conditions and increasing diversity and inclusion. Furthermore, the company aims to become fully circular and climate positive by 2040. Additionally, the company cooperates with different initiatives to develop policy-making and legislation for lowering negative environmental impact. The company's goal is also to raise companywide awareness of the negative environmental impact of carbon emissions to better focus on its reduction.
Secondly, the technology company Siemens (Germany) provides technological solutions and innovations worldwide. However, significant problems of all technological corporations include depletion of natural resources, massive energy use and electronic waste. The company works on automation, digitalization, intelligent infrastructure, smart mobility resources; it consists of three brands as Siemens AG, Siemens Energy and Siemens Healthineers. In the Sustainability Information report 2020 [18], prepared with the use of UN Guiding Principles Reporting Framework [19], it is declared that the company confirms the social and environmental responsibility to improve the working and production conditions and aims to apply the principles of circular economy through the entire product lifecycle. The German Independent Assurance Report confirms the report. The particular negative environmental impact concerns land use, air pollution, production of greenhouse gas as well as solid and liquid waste. So, the main focus for sustainable actions for Siemens attribures the strategies and practices to improve those factors and conditions. Additionally, Siemens focuses on their products quality characteristics, improving the reliability, quality and possibilities to repair or reuse. Last but not least, Siemens developed The Environmental Portfolio that works on the solutions for lowering environmental pollution and better resource use.

Thirdly, the mobile and electronic devices brand Apple (USA) that specialises in consumer electronics and software, presents its annual Environmental Progress Report 2020 [20]. Several independent auditor organizations confirm the report. The waste of mobile gadgets is one of those complicated pollutants that require proper analysis and reconsideration at the level of corporate social responsibility. The production of electronic devices requires a lot of natural resources and produces a lot of pre-consumer and post-consumer waste. Apple sets two primary goals: to achieve the carbon neutrality of the entire ecological footprint by 2030 (20 years ahead of the UN Intergovernmental Panel on Climate Change recommendations) and create products with net zero carbon impact by 2030. Moreover, Apple develops a 10-years climate roadmap that includes practices and solutions to implement low-carbon design and renewable energy sources, increase energy efficiency and carbon removal, and avoid direct carbon emissions in its facilities and supply chain.

\subsection{Ecological Footprint}

This factor represents the treatments and initiatives to reduce $\mathrm{CO} 2$-emissions. According to the Greenhouse Gas Protocol, it is possible to classify the emissions within 3 scopes. Scope 1 emissions define the carbon emissions from fuel combustion that a company operates; scope 2 emissions mention the greenhouse gas emissions from the electricity use (whether it is renewa- 
ble energy or fossil fuels used). Finally, scope 3 emissions represent all indirect emissions of a company that facilitate upstream and downstream activities.

H\&M Group provides the statistical data on the changes in $\mathrm{CO} 2$-emissions from own operations with a positive dynamic confirmed by the Science Based Targets initiative [21]: from $-21 \%$ in 2017 to $+18 \%$ in 2020 , to become climate positive by the latest 2040, H\&M Group performs impressive results by reducing greenhouse gas emissions to $40 \%$. Moreover, this fashion brand reduces the carbon emissions by transport supply chain $(12 \%$ reduction in 2020$)$. It is essential that the COVID-19 influence is also represented in the report: H\&M Group confirms that the lockdown and store closures over several months led to the decrease of carbon emissions. In order to attract the attention of potential investors and promote an opportunity to support some sustainable practices financially, H\&M Group launched a pilot for an internal carbon pricing model as well as a new green bond framework.

At Siemens, there is a goal to become carbonneutral by 2030 ; to achieve it, reducing greenhouse gas is incorporated in the key long-term company's initiatives. By successful practices and improved methods, Siemens improves the carbon emissions each year: from 2014 to 2020, own operations carbon emissions have been reduced by more than half. Moreover, in the supply chain, Siemens declares to reduce the carbon emissions by $20 \%$ by 2030 and to have a carbon-neutral supply chain by 2050 .

Apple declares becoming carbon-neutral for all worldwide operations and promises to become carbonneutral for the entire environmental footprint till 2030 by reducing emissions by $75 \%$ and investing in highquality carbon removing solutions. At Apple, they apply carbon reduction initiatives and invest in natural climate solutions to protect the environment. As a result, since 2015, Apple decreased its ecological footprint by $40 \%$. In addition, the low-carbon design of Apple products (materials use efficiency, increasing the energy efficiency of products) facilitates the analysis and treatments for decreasing its negative environmental impact.

\subsection{Energy Efficiency}

The goal to be energy efficient comprises different changes in the manufacturing process, including using less energy and performing the same task and reducing energy waste. The use of efficient energy sources improves greenhouse gas emissions and reduces the demand for energy import that may be even profitable for companies.

H\&M Group provides a positive dynamic of energy intensity, starting from $-2,7 \%$ in 2017 , having $-17 \%$ in 2020 and aiming to achieve $-25 \%$ by 2025 . By updating 288 stores in 28 markets with LED-lighting, the brand improves the indicators of energy efficiency. By developing the industrywide assessment tools, the fashion brand promises to improve the energy efficiency indicators constantly. Moreover, H\&M Group works with own production and supply chain in order to implement the practices of efficient use of energy resources. The fashion brand includes energy efficiency in its priority sustainable goals and aims to implement this principle to the entire value chain.

In 2015, Siemens Real Estate started a sustainability program for all locations around the globe in order to improve energy efficiency by 2020 . As a result, the energy cost decreased by approximately $€ 13$ million per year. In particular, the company aims to apply LED lighting and optimize building automation in order to facilitate cost reduction in office buildings worldwide. Moreover, some Siemens offices use distributed energy systems that combine cogeneration of solar energy, wind turbines, small turbines, smart energy management systems, and solutions to store energy. It is declared a goal to cover $10 \%$ of electricity requirements with the help of such distributed energy system. Furthermore, Siemens sets the goal to decrease the transportation carbon emissions and implement electro vehicles and appropriate conditions for its use. With the use of the Environmental Portfolio, Siemens enhanced the energy efficiency for the electricity use that energy-efficient products and solutions accounted for over $95 \%$ for the year 2020; those actions concerns the production processes and the user-phase operations.

At Apple, they achieve the reduction of the energy use due to the efficiency efforts and tracking and monitoring the energy use by all the facilities. Energy tracking and benchmarking, performance identification helps to utilize the energy more efficiently and productively. Moreover, through the Supplier Energy Efficiency and Supplier Clean Energy programs, Apple works with supplies regarding energy efficiency and reducing the use of electrical grids.

\subsection{Renewable Energy}

The use of renewable energy is essential both regarding sustainable resource use and the principles of reuse-reduce-recycle. Innovative clean energy that usually comes from natural resources (e.g., sunlight, wind, water) lowers carbon emissions and impacts less air pollution. Nowadays, various renewable energy options for industries create a new scope on sustainable development and its prospects.

H\&M Group notes that from 2017 the share of renewable energy use was growing from $95 \%$ to $96 \%$ in the following years, but in 2020 decreased to $90 \%$. However, the main goal is to achieve $100 \%$ of renewable energy use by 2030 as one of the priority sustainable goals for the company. In order to follow the new 
RE100's market boundary criteria, H\&M Group provides a balanced portfolio of energy attribute certificates, confirms the power purchase agreements on large-scale renewables projects and applies rooftop solar photovoltaic. Moreover, collaborating with logistics company Maersk, the fashion brand conducts the study of LEO fuel, ethanol and lignin mix, for its commercial and environmental profits to use in the future nearcarbon-neutral biofuel for shipping. Additionally, the fashion brand used in 2020 for the $20 \%$ of total shipping volume Maersk Eco Delivery fuel that is carbon-neutral and made from waste cooking oil. Last but not least, the project of climate-smart delivery (the use of electric vehicles and pedal cycles) and fossil-free fuels (the use of biogas and biodiesel) supports the general picture of brand's environmental contribution.

At Siemens, green electricity (biomass or wind power) provides more than $70 \%$ of the electricity demands. In addition, the company supports the initiatives to increase the use of renewable energy and accelerate the shift from fossil fuels to low-carbon energy sources.

At Apple, more than 100 suppliers use 100\% renewable energy sources; in the same way, they use $100 \%$ renewable energy for all Apple facilities. Moreover, Apple implements own renewable energy projects and invest in the long-term perspective in new wind energy projects. Normally Apple directly purchases renewable energy or uses renewable energy credits, investing in energy storage technologies.

\section{CONCLUSIONS}

This article presented the perspective on the notion of corporate social responsibility. This idea comprises strategies, tools and ideas for small and large companies to perform sustainable development. The importance of changes and implementation of sustainable technologies and solutions in the manufacturing process is crucial and attracts the global community's attention. Therefore, the possibility to join and present the results of sustainable transition is so much essential for many companies worldwide.

Environmental reports of corporate social responsibility usually represent the activities and changes of the companies that improve their public image and reputation. This article investigated the environmental reports for the year 2020 of three global corporations. Moreover, ecological footprint, energy efficiency and renewable energy became the main focus of the investigation. Firstly, the commitment of the fashion brand H\&M Group to sustainable energy use can be explained through the goal to become fully circular by 2040 and contribute to climate change by reducing greenhouse gas emissions in operations and the transport supply chain. Secondly, the sustainable development in energy use of the Siemens technological brand can be con- firmed by the goal to become carbon-neutral by 2030 and reducing the costs for energy use through the energy efficiency initiatives. Finally, the mobile and electronic devices brand Apple aims to achieve the carbon neutrality of the entire ecological footprint by 2030 by implementing a low-carbon design and constantly decreasing its ecological footprint.

These environmental reports demonstrate various possibilities for sustainable transition; they declare the need for changes and perform positive results of its implementation. It is essential, in particular, for large corporations to show a good example and offer visibility and transparency of the actions they involve. Corporate social responsibility describes companies' social, economic and environmental impact and can engage for responsible actions and sustainable solutions with substantial company profits and significant social and environmental benefits.

\section{REFERENCES}

[1] The Guardian, Revealed: the 20 firms behind a third of all carbon emissions. https://www.theguardian.com/environment/2019/oc t/09/revealed-20-firms-third-carbon-emissions.

[2] Fast Company, Coca-Cola, Nestlé, and PepsiCo are the world's biggest plastic polluters-again. https://www.fastcompany.com/90425011/cocacola-nestle-and-pepsico-are-the-worlds-biggestplastic-polluters-again.

[3] Forbes, Reducing Environmental Impact Is Now A Business Imperative. https://www.forbes.com/sites/deloitte/2020/01/22/r educing-environmental-impact-is-now-a-businessimperative/?sh $=4 \mathrm{c} 57 \mathrm{~b} 9 \mathrm{~b} 76 \mathrm{cc} 6$.

[4] MIT Sloan, Management Review, Why Sustainability Ratings Matter https://sloanreview.mit.edu/article/whysustainability-ratings-matter/.

[5] A. McWilliams, D.S. Siegel, P.M. Wright, Journal of Management Studies, 43(1) (2006) p. 1.

[6] L. Moir, Corporate Governance, 1(2) (2001) p. 16.

[7] P. E. Murphy, University of Michigan business review, 30(6) (1978) p. 19.

[8] A.B. Carroll, Archie B, Oxford Handbook of Corporate Social Responsibility, 2008 p. 19.

[9] M. A. Reynolds, K. Yuthas, Journal of Business Ethics, 78 (2008) p. 47.

[10] J.-M. Prado-Lorenzo, I. Gallego-Alvarez, I. M. Garcia-Sanchez, Corporate Social Responsibility and Environmental Management, 16(2) (2009) p. 94. 
[11] R. Benabou, J. Tirole, Economica, 77(305) (2010) p. 1.

[12] L. Bouten, P. Everaert, J. Christiaens, L. L. Van, M. L. De, Accounting Forum, 35(3) (2011) p. 187.

[13] T. S. Teck, A. Selvamalar, C. William, T. P. Liang, N. Karuppiah, Journal of Management and Sustainability, 10(1) (2020) p. 54.

[14] K. M. Shabana, A. K. Buchholtz, A. B. Carroll, Business \& Society, 56(8) (2017) p. 1107.

[15] Surface Mag, Can Prolific Polluter H\&M Solve Fashion's Waste Problem? https://www.surfacemag.com/articles/hm-greenmachine-recycling/.

[16] The Guardian, H\&M, Zara and Marks \& Spencer linked to polluting viscose factories in Asia. https://www.theguardian.com/sustainablebusiness/2017/jun/13/hm-zara-marks-spencerlinked-polluting-viscose-factories-asia-fashion.

[17] H\&M Group, Sustainability Performance Report 2020 . https://hmgroup.com/wpcontent/uploads/2021/03/HM-GroupSustainability-Performance-Report-2020.pdf.

[18] Siemens, Sustainability Information 2020. https://assets.new.siemens.com/siemens/assets/api/ uuid:d3a32709-674e-4d3f-92a3$8261402 \mathrm{fb} 27 \mathrm{~d} /$ Siemens-AG-NB-EN.pdf.

[19] UN Reporting Framework. https://www.ungpreporting.org/frameworkguidance/download-the-reporting-framework/.

[20] Apple, Environmental Progress Report 2020. https://www.apple.com/environment/pdf/Apple_En vironmental_Progress_Report_2021.pdf.

[21] Science Based Targets. https://sciencebasedtargets.org/set-a-target. 